W. TANG,* A. G. CAPACCI, X. Wei, W. Li, A. White, N. D. PATEL, J. SAVOIE, J. J. GAO,

S. RODRIGUEZ, B. QU, N. HADDAD, B. Z. LU, D. KRISHNAMURTHY, N. K. YEE,

C. H. SENANAYAKE (BOEHRINGER INGELHEIM PHARMACEUTICALS INC., RIDGEFIELD, USA)

Metal-Mediated

Synthesis

A General and Special Catalyst for Suzuki-Miyaura Coupling Processes

Angew. Chem. Int. Ed. 2010, 49, 5879-5883.

\title{
A Novel General Phosphine Ligand for Suzuki-Miyaura Cross-Coupling
}

\section{Key words}

phosphine ligands

Suzuki-Miyaura

cross-coupling
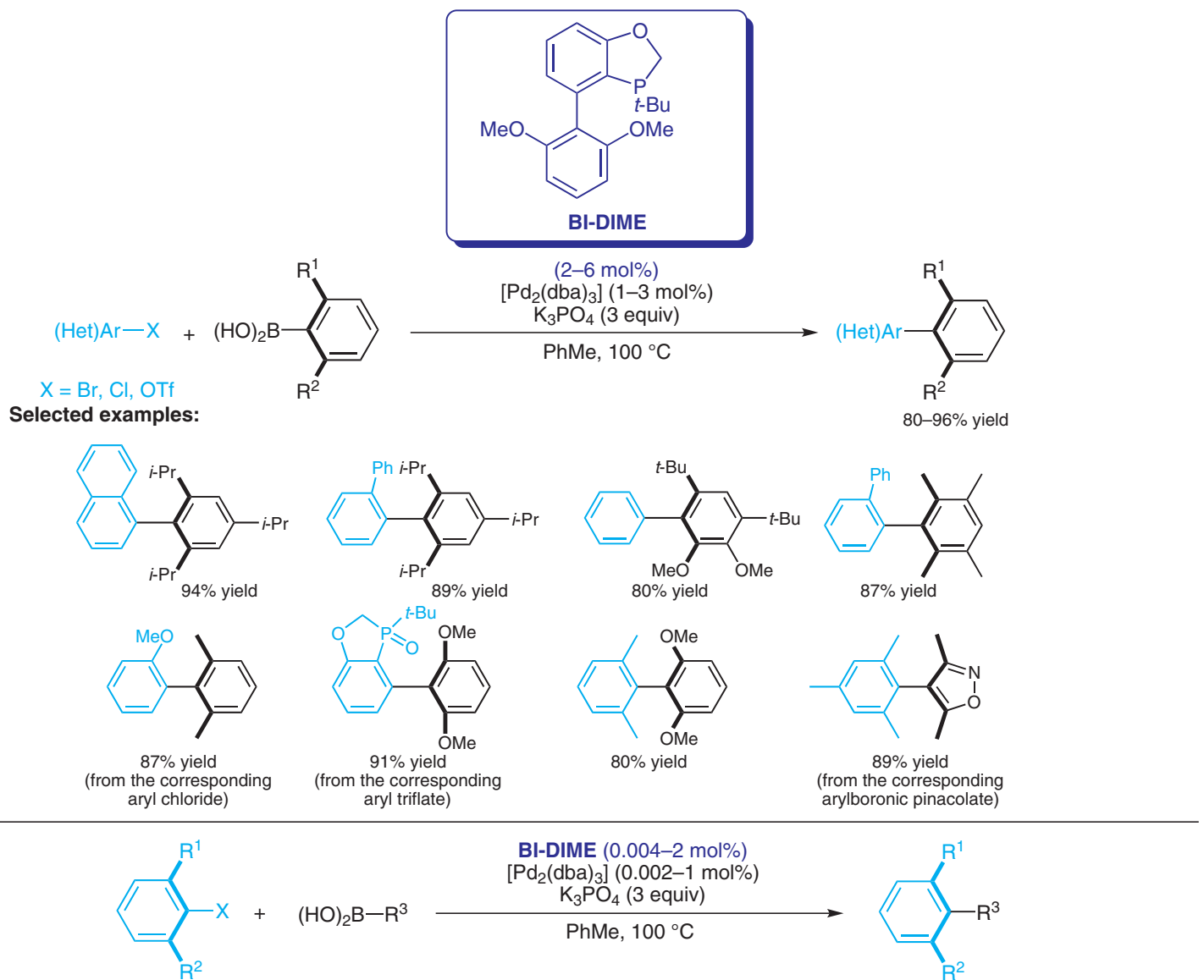

$\mathrm{X}=\mathrm{Br}, \mathrm{Cl}$

Selected examples:

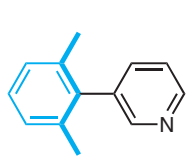

$95 \%$ yield

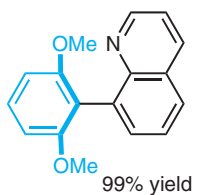

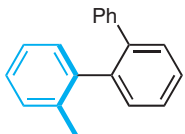

$98 \%$ yield (0.002 mol\% [Pd])

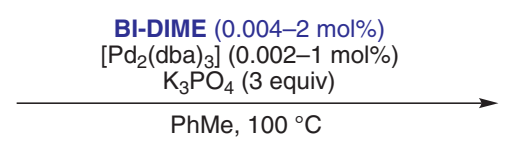

$\mathrm{PhMe}, 100^{\circ} \mathrm{C}$

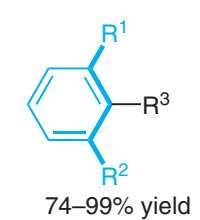

Significance: A new class of biaryl monophosphorous ligands with outstanding properties was developed. The ligand BI-DIME is highly air-stable and readily accessible in kilogram scale.
Comment: BI-DIME was tested as ligand in the palladium-catalyzed Suzuki-Miyaura reaction allowing for the first time the high-yielding crosscoupling of 2,4,6-triisopropylboronic acid with ortho-substituted aryl bromides.

SYNFACTS Contributors: Paul Knochel, Tobias Thaler DOI: 10.1055/s-0030-1258706; Reg-No.: P12410SF 